DOI: $10.20472 / S S .2020 .9 .1 .005$

\title{
RISK FACTORS AND RESISTANCE FACTORS: ALCOHOL CONSUMPTION AMONG NORMATIVE AND AT-RISK ADOLESCENTS IN ISRAEL
}

\author{
ZEEV KAIM, SHLOMO ROMI
}

\begin{abstract}
:
This study was designed to examine the risk factors and resistance factors involved in alcohol consumption among normative and at-risk adolescents. The study population included 211 at-risk adolescents and 271 normative high-school students. Participants filled in questionnaires on demographics, personality variables, and level of alcohol consumption. The research variables were selected in accordance with the four components of the Youth Resiliency model: having a significant adult in the child's life, positive daily experience in school, sense of self-worth, and sense of healthy social connectedness. The findings revealed similar variables leading to drinking in both groups, with heavier drinking in the at-risk group. Overall, religiosity was a major defense against drinking, although in the normative groups its protective effect was found only among older, financially stable adolescents. Being male, older, and holding a job were risk factors. Self-disclosure to parents, teachers, and friends was found to be a dichotomous contributor to drinking, so that the less adolescents disclose to parents and teachers and the more they disclose to friends, the more they drink. The main distinguishing personality variable between the two groups was avoidance, which contributed only among normative adolescents, acting as a defense against drinking. The significance of the findings and their applications are discussed.
\end{abstract}

\section{Keywords:}

Alcohol consumption, at-risk adolescents, religiosity, avoidance, self-disclosure

JEL Classification: D12, I12, Z12

\section{Authors:}

ZEEV KAIM, Hemdat HaDarom College, Israel, Email: zeev.kaim@gmail.com

SHLOMO ROMI, Bar Ilan University/Herzog College, Israel, Email: Shlomo.romi@biu.ac.il

\section{Citation:}

ZEEV KAIM, SHLOMO ROMI (2020). RISK FACTORS AND RESISTANCE FACTORS: ALCOHOL CONSUMPTION AMONG NORMATIVE AND AT-RISK ADOLESCENTS IN ISRAEL. International Journal of Social Sciences, Vol. IX(1), pp. 72-94., 10.20472/SS.2020.9.1.005 


\section{Introduction}

Alcohol consumption is among the risk behaviors with which adolescents experiment as they form their self-identity (Botvin \& Griffin 2007). A comprehensive survey conducted in Israel revealed that $12 \%$ of all adolescents smoke cigarettes, $28 \%$ drink, and $10 \%$ smoke hashish or marijuana (Harel-Fish, Steinmetz, Lubel \& Tessler 2014). Drinking has been associated with a wide range of health and behavioral risks, among them interpersonal violence, delinquency, unprotected sex, drug abuse, anti-social behavior, and low academic achievements (Botvin \& Griffin 2007). Furthermore, drinking strongly affects the health and behavior of others, in addition to affecting those of the alcohol consumer, and may lead to hospitalization, poisoning, road accidents, and death (NHS 2012).

Adolescents at risk are young people who are in physical, mental, emotional, or spiritual danger (Etzion \& Romi 2015). They are low achievers, have discipline and vagrancy problems, and move frequently among educational settings. They exhibit anti-social behavior patterns, a low frustration threshold and have a low self-image (Grupper \& Romi 2015). Within this group - a combination of a dangerous or criminal environment, a criminal or neglectful family, together with the adolescents' own personality factors, increase risk behaviors, among them overdrinking which is characteristic of adolescents under these circumstances who are a higher risk than others (Etzion \& Romi 2015), and therefore, for purposes of his study, will be defined as adolescents at risk.

\subsection{Alcohol consumption in adolescence}

Adolescents are at high risk for overdrinking and for its harmful symptoms (Merline, Jager \& Schulenberg 2008). Among adolescents, alcohol is the most prevalent drug for easing negative emotions, and it is consumed in many social situations (Bovtin \& Griffin 2007).

A longitudinal study that examined 18 risk factors for alcohol consumption and inebriation throughout adolescence revealed factors that were consistently related to drinking, among them parents who drink, using drugs, smoking cigarettes, absenteeism from school, aggressiveness, stealing, and vandalism (Merline et al. 2008). The literature indicates that these variables distinguish between adolescents at risk and their normative counterparts (Kaim \& Romi 2016).

In the present study, the Youth Resiliency model was used to select the research variables. The Youth Resiliency model refers to four main, universal resiliency factors that are the strongest and most consistent predictors of children and adolescents' wellbeing - having a significant adult in the child's life, positive daily experience in school, sense of self-worth, and sense of healthy social connectedness. The mental, social, and functional welfare of a child or adolescent who has had a positive experience with these four factors will be high, and the probability that this person would develop risk behaviors is very low (Harel-Fish 2014). The present study will focus on resiliency factors and risk factors that explain alcohol consumption among adolescents.

\subsection{Sociodemographic variables}

Socioeconomic status. Adolescents who live in poverty, in a dangerous or potentially harmful environment with patterns of risk behavior, are more likely to consume alcohol and drugs and act aggressively (Etzion 2010). However, the relationship between socioeconomic status and consuming psychoactive substances is age related, and during adolescence, it is lower socioeconomic status that is related to such use (Etzion 2010; Horowitz \& Brosh 2011). 
Age. The rate of drinking increases as adolescents grow older (Harel-Fish et al. 2014; Tessler 2015), and their perception of drinking may directly affect when they will begin drinking and the nature of their drinking (Van der Vorst \& Engels 2006). Adolescents who began drinking when they were 13 or older showed fewer alcohol-related problems than those whose drinking began at an earlier age (Werch et al. 2001), and who were also more likely to develop alcohol dependence (Van der Vorst \& Engels 2006).

Gender. Drinking is more prevalent among boys of all ages than among girls, although the gap narrows with age (Harel-Fish et al. 2014; Patrick \& Schulenberg 2014; Tessler 2015). Adolescent boys overdrink (Harel-Fish et al. 2014) and engage in more negative outcomes of drinking than girls (Tessler 2015). In a study of the relationship between 18 risk factors to drinking and inebriation, stronger correlations were found among male students than among their female counterparts (Merline et al. 2008), perhaps because among boys there are greater distortions of judgement, leading them to believe that they are invincible and immortal (Alberts, Elkind \& Ginsberg 2007). Additionally, adolescent boys, more than girls, tend to externalize and exhibit negative and aggressive behavior (Gullone \& Moore 2000). Furthermore, the motivation for drinking is different - boys are primarily influenced by their peers, and for girls, drinking is associated with emotional difficulties resulting from abuse, low self-esteem, and their relationship with their parents (Etzion 2010; Michael \& Ben-Zur 2007).

Religiosity. In the three monotheistic religions, religiosity is a major protective factor against drinking and its negative implications (Dagan 2016; Michalak, Trocki \& Bond, 2007; Piko, Kovacs, Kriston \& Fitzpatrick 2012; Tessler 2015). A study of the correlation between alcohol consumption and religiosity variables (religious affiliation, religious cult, church membership, faith, private prayer, and welfare) among Christian adolescents revealed that expressions of religiosity were negatively related to a low rate of drinking (Piko et al. 2012). Hodge et al. (2011) found that religious identity and being part of a religious network are predictors of less use of psychoactive substances, but this finding was not confirmed by the measure of internalized religious values. Dagan (2016) and Kipnis (2014) found that religiosity was a mitigating factor for drinking among Jewish adolescents and students, with both studies making a distinction between ritual consumption and drinking in other situations.

\section{Personality variables}

Self-esteem. Research conducted among students revealed a correlation between low selfesteem and drinking (DeHart, Tennen, Armeli, Todd \& Mohr 2009; Korn \& Maggs 2004). Low self-esteem is related to a lower sense of the risk inherent in drinking (Neumann, Leffingwell, Wagner, Mignonga \& Mignonga 2009), to a belief that drinking enhances one's social position (Korn \& Maggs 2004) and helps deal with negative emotional situations (Backer-Fulghum, Patock-Peckhan, King, Roufa \& Hagen 2011). These findings are consistent with the vulnerability theory, which proposes that people with low self-esteem are more vulnerable to negative experiences, and those with high self-esteem are more resilient in negative situations (Zwigler-Hill 2011).

Attachment style. Insecure attachment styles are a risk factor for alcohol consumption and its negative implications. In a study conducted among students, the researchers examined two types of motivation to overdrink - as a social need, (Molnar, Sadava, DeCourville \& Perrier 2010). The social need was driven by a search to belong to a group and avoid rejection, and the excitation - strengthening positive emotions and paralyzing negative ones (emotional regulation). Individuals whose attachment style was avoidant, showed statistically significant correlations with low scores of social motivation as an incentive to drink. Conversely, individuals 
whose attachment style was anxious showed statistically significant correlations with social and emotional motivation to drink.

Kassel, Wardle, and Roberts (2006) found that the correlation between insecure attachment and consuming psychoactive substances was mediated by low self-esteem and defective attitudes toward oneself. They concluded that individuals whose attachment styles are insecure lack essential skills for social relationships, which can lead to distress or anxiety. In addition, such individuals have a lower chance of being involved in positive relations with a supportive partner. Therefore, during stressful periods, they escape to psychoactive substances.

An earlier study (Brennan, Shaver \& Tobey 1991) revealed that people whose attachment style is insecure are heavier drinkers than people with secure attachment styles. Other studies yielded similar results, namely that participants with an anxious-ambivalent attachment style reported more significantly of overdrinking and its ensuing negative implications than did those with avoidant and secure attachment styles (Monlar et al. 2010). These findings underscore the importance of attachment style as a risk factor for using psychoactive substances, especially alcohol.

Self-disclosure. Self-disclosure changes during adolescence, as adolescents begin turning more to peers and less to parents (Vogel \& Wei 2005). At the same time, even during this period, a high correlation was found between warm and close relationships with parents and adolescents' tendency to disclose to their parents, friends and teachers (Grabill \& Kerns 2000). In times of stress, adolescents express their distress by turning to their friends, thus recruiting social and emotional support (Buhrmester \& Prager, 1995). While self-disclosure is an important emotional outlet, it can also have negative aspects, such as social rejection, criticism, loss of power, and negative esteem (Apter, Horesh, Gothelf, Graffi \& Lepkifker 2001). One's inability to expose emotions and thoughts to close people could be a risk factor for suicidal behavior and mental disorders (Apter et al. 2001).

Effect of family and friends. Adolescents' experiences with alcohol consumption and other risk behaviors is affected by the quality of their relationships with their family and friends (Kurt \& Ergene 2017). Parental supervision and monitoring were found to be a protective factor related to lower alcohol consumption (Dever et al. 2012; Jessor, Costa, Krueger \& Turbin 2006), especially among adolescents who drink frequently and tend to get drunk (Dever et al. 2012). It was also found that drinking with friends is among the prominent predictors of overdrinking during adolescence (Jessor et al. 2006; Patrick, Schulenberg, Maggs \& Maslowsky 2012; Tessler 2015), as adolescents who drink influence others to join them (social pressure), and those who drink prefer to hang out with drinkers like themselves (Patrick et al. 2012).

A study of the unique effects of family and friends, revealed that positive relations between adolescents and their parents, family support, and a positive and cohesive atmosphere devoid of conflict all prevent adolescents from distancing themselves from the family and lower the likelihood of attaching themselves to peers who use alcohol and psychoactive substances. A conflictual family relationship could encourage connecting to adolescents from marginal groups who are also searching for a relationship that will compensate for their defective family system, and lead the adolescent to various risk behaviors (Etzion 2010; Jessor et al. 2006). Furthermore, lack of strong and stable mechanisms of control and authority within these families, and parents' noninvolvement in the lives of their adolescent children increase risk behaviors (Adler \& Wazner 2005; Kurt \& Ergene 2017).

The peer group, which gains significance during adolescence, may shape negative behavioral norms and is a source of temptation and risk taking, especially when adolescents want to impress others and gain social status with their risk behaviors. Adolescents who are involved 
with risk-taking peers are likely to engage in such behaviors, and these peer relations can be better predictors of risk behavior than parental influence (Jessor et al. 2006). However, while adolescents' social settings affect their drinking patterns, most adolescents who drink do so for fun and as a pastime and not as an expression of a mental or social problem. Horowitz and Brosh (2011) found that normative adolescents tended to point to social pressure as a reason for drinking, whereas adolescents at risk were more likely to describe reasons related to escapism and feeling good.

Attitudes toward alcohol and drugs of people who are important to the adolescent are strongly correlated to the adolescent's attitude and actual drinking. Evidence suggests a correlation between parents' risk behaviors and alcohol, drug, and tobacco use and their children's behavior, enhancing the idea of intergenerational transference (White, Johnson \& Buyske 2000). Furthermore, adolescents' perception of their parents' behavior affects their behavior more than the parents' actual behavior (Parker \& Benson 2004).

\subsection{The effect of school and work during adolescence}

Drinking is also related to the adolescent's situation in school. Failure in school, detachment, absenteeism, and misbehavior have all be found to be positively correlated to the consumption of alcohol and psychoactive substances (Bryant et al. 2003; Dever et al. 2012; Patrick \& Schulenberg 2012). A longitudinal study of predictive factors for drinking among eighth-grade students revealed that misbehavior, and encouraging friends to behave similarly, are positively correlated to using psychoactive substances; a positive attitude toward school, good academic achievements, and receiving parents' help with studies were negatively correlated to such use (Bryant et al. 2003).

Many adolescents work in addition to being in school or in CYC settings. Such work (usually after school hours or on weekends) can be a contribution to the family income, or because adolescents want to have their own money (REF).

The connection between working and alcohol consumption among adolescents and students is complex. On the one hand, a commitment to work can reduce alcohol consumption due to the lack of opportunities to attend social events involving alcohol consumption (Lepple, 2006). On the other hand, multiple hours of work have been associated with an increase in alcohol consumption (Adam, Butler, Dodge, \& Faurote, 2010; Staff et al. 2010). Bachman et al. (2010) found that sociodemographic and educational characteristics control the positive connection between the number of working hours and drinking, perhaps because long working hours lead to detachment from school.

The review of the literature revealed that the two groups - normative and at-risk adolescents differed in background, coping resources, and the nature of their relationships with significant designed to examine the variables (risk factors and resistance factors) that explain alcohol consumption in these two groups. The variables selected refer to the Youth Resilience model, and the research literature found them to be main risk factors and resistance factors for all risk behaviors, especially alcohol consumption. Additionally, most of these measures may point to appropriate interventions to reduce risk behaviors through enhancing the mental and social welfare of students, parents, and teachers. Understanding these two factors could expand our knowledge of adolescent drinking and map the risk factors and resistance factors to predict it. With this information, youth-at-risk units could construct preventive programs and interventions appropriate for their adolescents. This study is unique in that a comparison is made between the contribution of the variables to explain the variance of alcohol consumption among adolescents at risk with that of normative adolescents. 


\section{Method}

\subsection{Population}

The study was conducted in Israel, and the sample included 482 Jewish adolescents, age 14$18(M=16.06, S D=1.19)$. Of these, 211 were adolescents at risk from Child and Youth Care (CYC) Units, and 271 normative adolescents, all high-school students. Participants' personal characteristics are presented in Table 1.

Table 1: Distributions of Participants among Adolescents at risk and Normative Adolescents by Personal Characteristics ( $n, \%)$

\begin{tabular}{|c|c|c|c|c|c|c|}
\hline \multirow[t]{2}{*}{ Characteristics } & \multirow[t]{2}{*}{ Values } & \multicolumn{2}{|c|}{$\begin{array}{c}\text { Adolescents } \\
\text { at risk }\end{array}$} & \multicolumn{2}{|c|}{$\begin{array}{l}\text { Normative } \\
\text { adolescents }\end{array}$} & \multirow[b]{2}{*}{$\chi^{2}$} \\
\hline & & $n$ & $\%$ & $n$ & $\%$ & \\
\hline \multirow[t]{2}{*}{ Gender } & Male & 132 & 62.6 & 152 & 56.1 & \multirow[t]{2}{*}{2.05} \\
\hline & Female & 79 & 37.4 & 119 & 43.9 & \\
\hline \multirow{3}{*}{$\begin{array}{l}\text { Parents' } \\
\text { education }\end{array}$} & Elementary & 48 & 22.7 & 32 & 11.8 & \multirow[t]{3}{*}{$37.40^{* * *}$} \\
\hline & High school & 125 & 59.2 & 121 & 44.6 & \\
\hline & $\begin{array}{l}\text { Higher } \\
\text { education }\end{array}$ & 38 & 18.0 & 118 & 43.5 & \\
\hline \multirow{3}{*}{$\begin{array}{l}\text { Parents' marital } \\
\text { status }\end{array}$} & Married & 114 & 54.0 & 232 & 85.6 & \multirow[t]{3}{*}{$58.62^{* * *}$} \\
\hline & Divorced & 84 & 39.8 & 35 & 12.9 & \\
\hline & Widowed & 13 & 6.2 & 4 & 1.5 & \\
\hline \multirow{3}{*}{$\begin{array}{l}\text { Parents' } \\
\text { socioeconomic } \\
\text { status }\end{array}$} & Poor & 58 & 27.5 & 46 & 5.9 & \multirow[t]{3}{*}{$61.59^{* \star *}$} \\
\hline & Average & 64 & 30.3 & 54 & 19.9 & \\
\hline & Good & 89 & 42.2 & 201 & 74.2 & \\
\hline
\end{tabular}

${ }^{* \star *} p<.001$

The $\chi^{2}$ analyses conducted to examine the differences between the two groups, yielded statistically significant differences for all characteristics of the participants' parents. The parents of adolescents at risk were less educated than the parents of the normative group, and more participants in the at-risk group came from families where the parents are divorced or widowed.

Adolescents at risk came from smaller families, and their socioeconomic situation was not as good as that of their normative counterparts. No significant differences were found regarding gender - there are more boys than girls in both groups. A previous study (Kaim \& Romi 2015) revealed significant differences regarding risk behaviors.

A $t$ test revealed a significant age difference between the two groups $-t=15.09, p<.001$, with adolescents at risk being older $(M=16.82, S D=1.03)$ than their normative counterparts $(M=$ $15.46, S D=.91)$. These differences were taken into consideration in the statistical analyses. 


\subsection{Tools}

The research tool was a five-part questionnaire:

1. Personal characteristics questionnaire. Of the 23 items in this questionnaire, 17 pertain to the participants and 6 to their families. A 4-point Likert scale was used to rate the degree to which participants worked (1 - do not work, 4 - full-time job). The frequency of alcohol consumption was rated on a 5-point Likert scale (1-never, 5-regularly), with higher scores indicating more frequent use.

2. Self-esteem questionnaire (Rosenberg 1965). This 10-item questionnaire examines overall self-esteem, with answers rated on a 5-point Likert scale (1 - strongly disagree, 5 - strongly agree). Five items refer to positive self-esteem and five to negative self-esteem. The items pertain to the individual's life satisfaction, positive attributes, positive self-perception, a sense of being needed and useful, and the degree of self-respect or failure the individual feels. For example, an item related to negative self-esteem is "Sometimes I feel I'm not worth a thing." The score is reached by calculating the average of answers to all items, with reversed coding for negative items. Higher averages indicate higher self-esteem. Internal consistency for this questionnaire in high $-\alpha=.85$.

3. Attachment-style questionnaire (Kaduri 2005), is based on Brennan, Clark, and Shaver's (1998) Experience in Close Relationship questionnaire. The questionnaire defines attachment style using two consecutive ultra-dimensions of attachment - avoidant and anxious - and uses them to present four styles: Secure, anxious-avoidant, anxious, and avoidant. The original questionnaire has 36 self-report items, half related to anxious attachment and half to avoidance. The 16 items in the shortened questionnaire described adolescents' sense of close relationship on a 7-point Likert scale (1 - not at all, 7 - very much). The eight odd-numbered items examine avoidant attachment style (e.g, "I prefer not to show other people how I feel"), and the eight even-numbered examine anxious attachment style (e.g, "I'm worried that I'll lose people close to me").

Internal consistency for this questionnaire in the present study was intermediate $(\alpha=.72)$ for avoidant and good ( $\alpha=.81$ ) for anxious. Anxious and avoidant scores were calculated by the average scores for the items in each measure. Higher scores indicated higher avoidance or anxious attachment.

4. Self-disclosure questionnaire (Shulman, Laursen, Kalman \& Karpovsky 1997). This 24-item questionnaire addressed the degree of adolescents' disclosure in three main realms - family, social ties, and body image. Each realm had eight items, and participants were asked to assess on a 4-point Likert-type scale ( 1 - I don't really share, 4 - usually share) the degree to which they share with three central figures in their lives - parents, friends, and teachers. A high level of sharing represents high self-disclosure. The present study used general scales, both for their high reliability and the strong correlations among the three realms in each scale. Internal consistency for each figure in this study was high $-\alpha=.95$ for disclosure to family, $\alpha=.95$ for friends, and $\alpha=.97$ for disclosure to teachers.

5. Mastery questionnaire. Participants' sense of mastery was examined using a questionnaire constructed by Pearlin and Schooler (1978). The seven items describe the participant's sense of mastery on a 7-point Likert scale (1 - not appropriate, 7 - very appropriate). Participants' average answers make up their score, with a high score indicating a high sense of mastery. 


\subsection{Procedure}

The researchers applied for permission to the Israeli Ministry of Education, and having received it, contacted 20 directors of CYC UNITS, and 15 school principals; 13 directors and 6 principals agreed to participate. Sampling was done by the cluster method, so that three grade levels (9th, 10 th, and 11th) were sampled in each school and one class chosen from each level; in the CYC UNITS, one half of the adolescents, randomly selected (age 14-18) were sampled. It was made clear to the participants that the questionnaires were anonymous and for purposes of this study only. These explanations were intended to enhance their willingness to answer candidly, thus increasing the study's reliability.

Of the 723 questionnaires distributed to participants in their educational settings, $656(91 \%)$ were returned fully completed. Of these, 63 filled in by adolescents at risk and 111 filled in by normative adolescents were discarded, as the respondents were not within the age range (1418) set for this study. The final count was 211 adolescents at risk and 271 normative adolescents. Participants spent an average of 40 minutes answering the questionnaires.

\section{Results}

\subsection{Differences between the research groups}

To examine whether there are differences in alcohol consumption between normative adolescents and at-risk adolescents by personal characteristics (gender, marital status, and work), a 2 x 2 ANOVA (groups $x$ personal characteristics) was conducted. The ANOVA yielded a significant difference between adolescents at risk and their normative counterparts, $F(1,473)$ $=62.47, p<.001, E t a^{2}=.12$. Adolescents at risk drink more $(M=2.23, S D=.93)$ than normative adolescents $(M=1.64, S D=.85)$.

Significant differences found regarding gender, $F\left(1,473=15.47, p<.001\right.$, $\operatorname{ta}^{2}=.03$, and work $F\left(1,473=27.85, p<.001, E t a^{2}=.06\right.$. The findings reveal that boys drink more than girls $(M=$ 2.08, $S D=.95$ and $M=1.73, S D=.90$, respectively), and that working adolescents drink more than those who do not hold a job $(M=2.25, S D=.93$ and $M=1.68, S D=.88$, respectively). It should be noted that these analyses yielded no statistically significant interactions.

Inter-measure correlations. To examine the correlation between the research measures and drinking, Pearson correlations were calculated for all participants and for each group separately. Following are the findings for the entire sample. When Fisher's $Z$ analyses revealed a significant difference between the correlations for the adolescents at risk and the normative adolescents, each group is also reported on separately.

Pearson correlations were calculated for the continuous personality characteristics (age, religiosity, and socioeconomic status), and significant positive correlations were found between age and level of drinking in both groups $(r=.38, p<.001)$. Significant negative correlations were found between drinking and level of religiosity $(r=-.28, p<.001)$ and socioeconomic status $(r$ $=-.20, p<.001)$. In other words, the older the adolescents, and the lower they defined their level of religiosity and socioeconomic status, the higher their level of drinking. It should be noted that, Fisher's $Z$ analyses did not yield significant differences between the two groups.

Pearson correlations were calculated to examine the relationships between the various research measures for all participants and for each group separately. These correlations are presented in Table 2. 
Table 2: Pearson's correlations between study variables

\begin{tabular}{|lcccccccc|}
\hline & Avoidance & Anxious & Mastery & $\begin{array}{c}\text { Self- } \\
\text { esteem }\end{array}$ & $\begin{array}{c}\text { Self- } \\
\text { disclosure } \\
\text { to parents }\end{array}$ & $\begin{array}{c}\text { Self- } \\
\text { disclosure } \\
\text { to friends }\end{array}$ & $\begin{array}{c}\text { Self- } \\
\text { Disclosure } \\
\text { to } \\
\text { teachers }\end{array}$ & Drinking \\
\hline Avoidance & 1.00 & & & & & & & \\
Anxious & $.20^{* * *}$ & 1.00 & & & & & \\
Mastery & -.08 & $-.15^{* *}$ & 1.00 & & & & \\
Self- & $-.31^{* * *}$ & $-.46^{* *}$ & $.23^{* * *}$ & 1.00 & & & \\
esteem & & & & & & & \\
Self- & $-.30^{* * *}$ & .01 & .01 & .13 & 1.00 & & \\
disclosure & & & & & & & \\
to parents & & & & & & & \\
Self- & $-.32^{* * *}$ & .13 & -.05 & -.10 & $.45^{* * *}$ & 1.00 & \\
disclosure & & & & & & & \\
to friends & & & & & & & \\
Self- & $-.27^{* * *}$ & .12 & -.12 & .08 & .11 & .07 & 1.00 \\
disclosure & & & & & & & \\
to teachers & & & & & & & \\
Drinking & -.06 & .08 & -.02 & -.13 & -.09 & $.23^{* * *}$ & $-.25^{* * *}$ & 1.00 \\
$M$ & 3.49 & 3.45 & 4.41 & 3.13 & 2.37 & 2.38 & 2.36 & \\
$S D$ & 1.03 & 1.31 & .98 & .55 & 7.30 & 7.58 & 1.52 & \\
\hline
\end{tabular}

${ }^{\star} p<.05 .{ }^{* \star} p<.01 .{ }^{\star * *} p<.001$.

As seen in Table 2, the correlations between all variables and the alcohol-consumption variable, which is the dependent variable in this study, revealed significant correlations only between selfdisclosure to friends and teachers and level of drinking. The highest correlation is with selfdisclosure to friends. According to the correlations, the more adolescents are prepared to expose themselves to friends, the more they turn to heavier drinking. In addition, a negative correlation was found between self-disclosure to teachers and alcohol consumption - the more adolescents are willing to disclose themselves to a teacher, the less alcohol they drink.

Regarding the two attachment variables, significant negative correlations were found between avoidance and self-esteem. Negative correlations were found between avoidance and selfdisclosure to parents, friends, and teachers. These correlations seem to indicate that the more adolescents are characterized by avoidance, the lower their self-esteem and willingness to expose their feelings.

Negative correlations were also found between anxious attachment style and self-esteem and mastery. According to these correlations, the more adolescents are characterized by higher anxiety, the lower their self-esteem and sense of mastery.

A positive correlation was found only between mastery and self-esteem, so that adolescents with higher mastery of their lives also have more self-esteem.

A significant positive correlation was found between self-disclosure to parents and selfdisclosure to friends. The more adolescents expose themselves to their parents, the more they do so for friends.

To examine whether there are differences between the groups regarding the relationships between the various measures, Fisher's $Z$ analyses were conducted. These analyses revealed a significant difference between the groups only regarding the correlation between avoidance 
and drinking $(Z=2.46, p<.01)$. Among normative adolescents a significant negative correlation was found between avoidance and drinking $(r=.21, p>.001)$, whereas among the adolescents at risk the correlation was very low and not significant $(r=.02, p<.05)$. It seems that the higher the avoidance measures of normative adolescents, the less alcohol they consume.

\subsection{Regression analyses}

To examine the contribution of variables to explaining the alcohol consumption among normative and at-risk adolescents, we conducted hierarchical regression analyses where the dependent variable was the degree of alcohol consumption. The predictive variables were added as a four-step process: (1) the personal characteristics that were found to be related to drinking, (2) attachment measures, (3) self-disclosure measures, and (4) interactions of personal characteristics $x$ measures. It should be mentioned that the self-esteem variable was first entered in the regression analysis, but because it was not found to significantly contribute to explaining the variance, it was not included in the final regression

To examine whether the contribution of the variables is dependent upon personal characteristics, the interaction between the personal characteristics was calculated, as was the interaction between personal characteristics and personal resources. It should be noted that for the first three steps, entering the steps was forced, while in Step 4, where the contribution of the interaction was examined, the variables were entered according to the statistical significance of their contribution to explaining variance. Here, three interactions were found to contribute significantly only in the normative group - age $\mathrm{x}$ religiosity, socioeconomic status $\mathrm{x}$ religiosity, and work $x$ self-disclosure to friends. The hierarchical regression analysis for explaining the variance in alcohol consumption is presented in Table 3.

Table 3: Regression Coefficients Explaining the Variance of Drinking among Adolescents in Risk $(n=211)$ and among Normative Adolescents $(n=271)$

\begin{tabular}{|c|c|c|c|c|c|c|c|}
\hline \multirow[t]{2}{*}{ Step } & \multirow[t]{2}{*}{ Predictors } & \multicolumn{3}{|c|}{ Normative Adolescents } & \multicolumn{3}{|c|}{ Adolescents in Risk } \\
\hline & & $\beta$ & $\mathrm{R}^{2}$ & $\Delta R^{2}$ & $\beta$ & $\mathrm{R}^{2}$ & $\Delta \mathrm{R}^{2}$ \\
\hline \multirow[t]{5}{*}{ I } & Gender & $-.16^{*}$ & $.20^{\star * *}$ & $.20^{\star \star *}$ & $-.16^{\star}$ & $.19^{\star \star \star}$ & $.19^{\star * \star}$ \\
\hline & Age & $.16^{*}$ & & & $.22^{* *}$ & & \\
\hline & Religiosity & $-.27^{\star * *}$ & & & $-.25^{\star * *}$ & & \\
\hline & Socioeconomic status & .00 & & & $-.15^{\star}$ & & \\
\hline & Work & $.22^{* * *}$ & & & $.16^{*}$ & & \\
\hline \multirow[t]{2}{*}{ II } & Avoidance & $-.25^{\star * \star}$ & $.26^{* * *}$ & $.06^{*}$ & -.04 & $.19^{\star \star *}$ & .00 \\
\hline & Anxious & .12 & & & .06 & & \\
\hline \multirow[t]{3}{*}{ III } & Self-disclosure to parents & $-.20^{* *}$ & $.36^{* * *}$ & $.10^{\star \star \star}$ & $-.26^{\star *}$ & $.30^{\star \star \star}$ & $.11^{* * *}$ \\
\hline & Self-disclosure to friends & $.29^{\star \star *}$ & & & $.33^{\star \star \star}$ & & \\
\hline & $\begin{array}{l}\text { Self-disclosure to } \\
\text { teachers }\end{array}$ & $-.25^{\star *}$ & & & $-.22^{* *}$ & & \\
\hline
\end{tabular}




IV $\begin{array}{llll}\text { Age } \times \text { Religiosity } & -.22^{* * *} & .43^{* * *} & .07^{* \star} \\ \text { Work } \times \text { Self-disclosure to } & .18^{* *} & \\ \text { friend } & \\ \text { Religiosity } \times & -.19^{* *} \\ \text { Socioeconomic status } & & \end{array}$

$$
{ }^{*} p<.05 .{ }^{* *} p<.01 .{ }^{* *} p<.001 .
$$

As seen in Table 3, in the first step where personal characteristics (gender, age, religiosity, socioeconomic status, and work) were entered, a similar contribution was found for both groups $-20 \%$ among normative adolescents and $19 \%$ adolescents at risk. The groups are also similar in that in both, all personal characteristics contribute similarly - and significantly. The one exception is the socioeconomic status, which contributed only to the adolescents at risk. In both groups, there is a higher rate of drinking among boys than among girls. In addition, age and work contribute significantly to explain variance: Older adolescents drink more, and more hours of work are correlated with more drinking. In both groups, the more religious the adolescents, the less they drink. Socioeconomic status was a contributor only among adolescents at risk, with better socioeconomic standing related to less drinking.

Two attachment measures (anxious and avoidant) were added to the regression in Step 2, and a statistically significant contribution of $6 \%$ for variance was found only among normative adolescents. In the normative group, only avoidance was found to have a significant contribution, so that the more the adolescents are characterized by avoidance, the less they drink.

The three measures of self-disclosure (to parents, friends, and teachers), which were entered in Step 3, made a significant $(10 \%)$ contribution to explain variance among normative adolescents and $11 \%$ among adolescents at risk. All self-disclosure variables (to parents, friends and teachers) were significant $-\beta$ to parents and teachers were negative and $\beta$ to friends, positive. Thus, the less participants disclose to their parents and their teachers and the more to their friends, the more they drink.

The interactions of personal characteristics $\times$ measures were entered in the Step 4, and yielded a significant contribution of $8 \%$ only among normative adolescents. Three interactions were found to contribute significantly in this group - age $\times$ religiosity, socioeconomic status $\times$ religiosity, and work $\times$ self-disclosure to friends. The interaction of age $x$ religiosity is presented in Figure 1. 
Figure 1. Correlations between Religiosity and Drinking among Older and Younger Adolescents

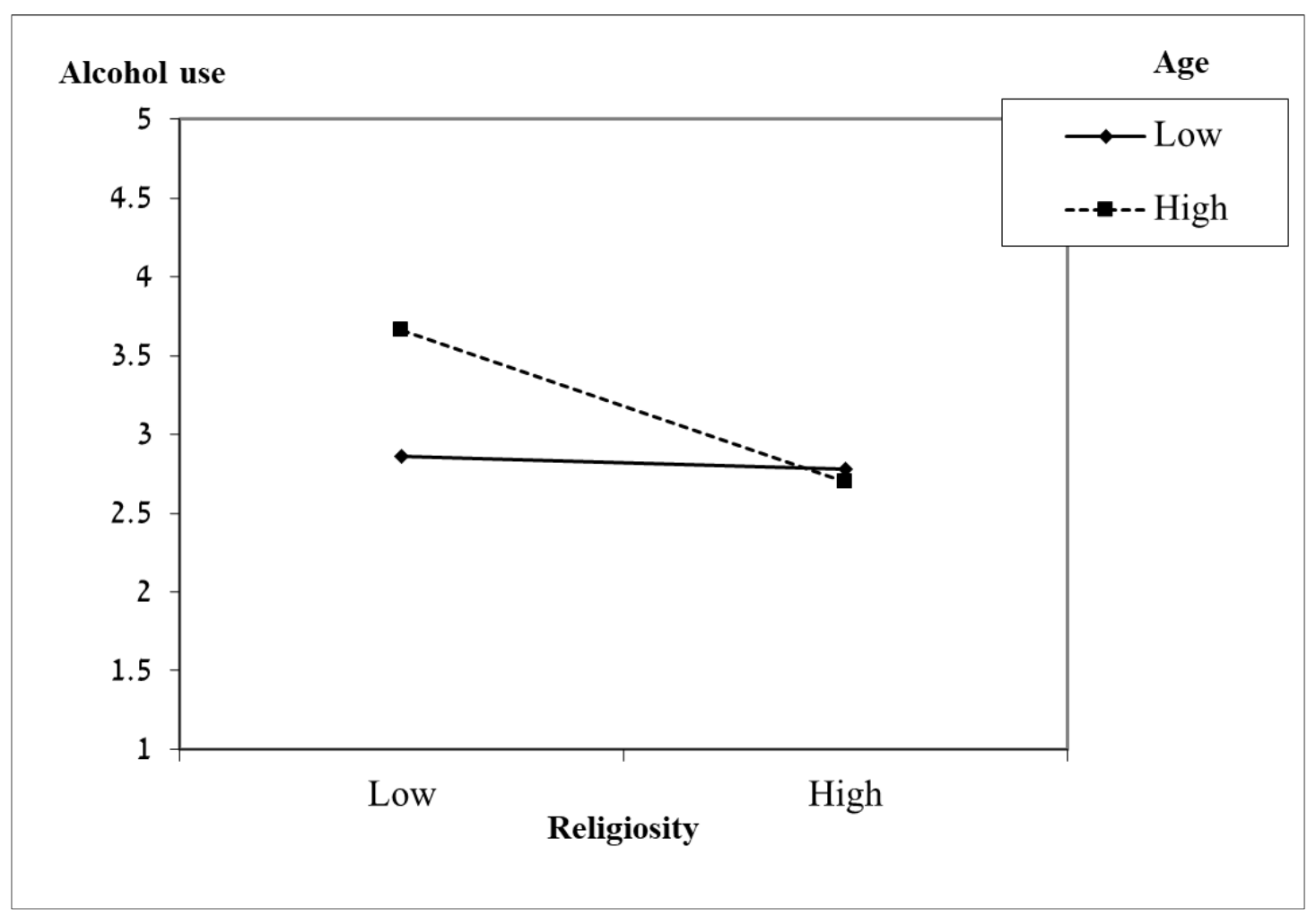

As seen in Figure 1, a significant negative correlation between level of religiosity and drinking $(\beta=.36, p<.001)$ was found among older adolescents, a correlation among their younger peers was weak and not significant $(\beta=-.01, p<.05)$. In other words, the more religious the older adolescents are, the less they drink. In addition, a significant interaction was found for socioeconomic status $\times$ religiosity, as seen in Figure 2 . 
Figure 2: Link between Religiosity and Alcohol Consumption among Adolescents of High and Low Socioeconomic Status

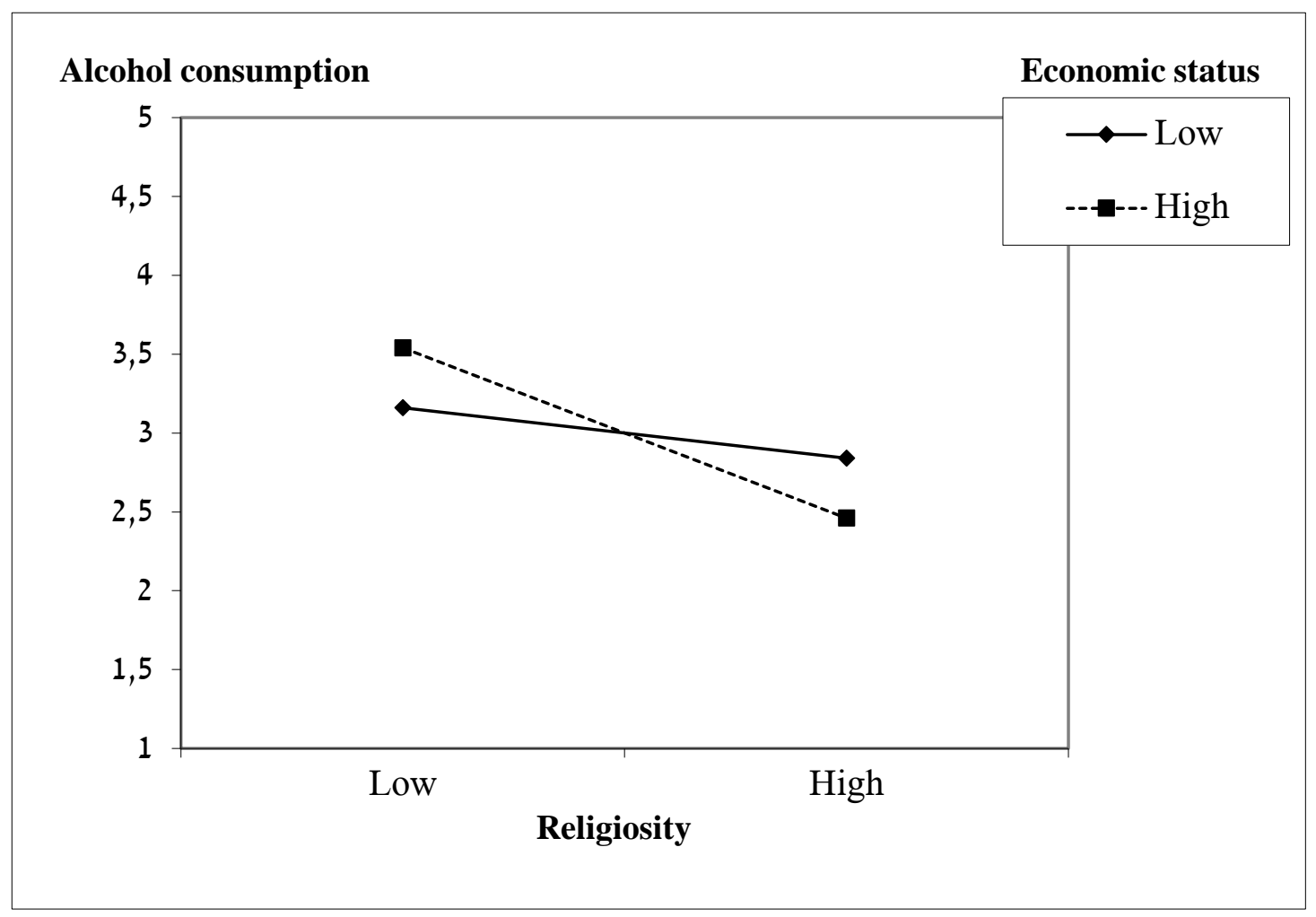

As seen in Figure 2, among adolescents of a high socioeconomic status, there was a significant negative correlation between level of religiosity and drinking $(\beta=-.34, p<.001)$, with higher religiosity related to less drinking. Conversely, among participants of low socioeconomic status, no significant correlation was found between level of religiosity and amount of drinking $(\beta=-$ $.09, p<.05)$. Another interaction was work $\times$ self-disclosure to friends, presented in Figure 3. 
Figure 3: Correlation between Self-disclosure to Friends and Drinking among Working and not Working Adolescents

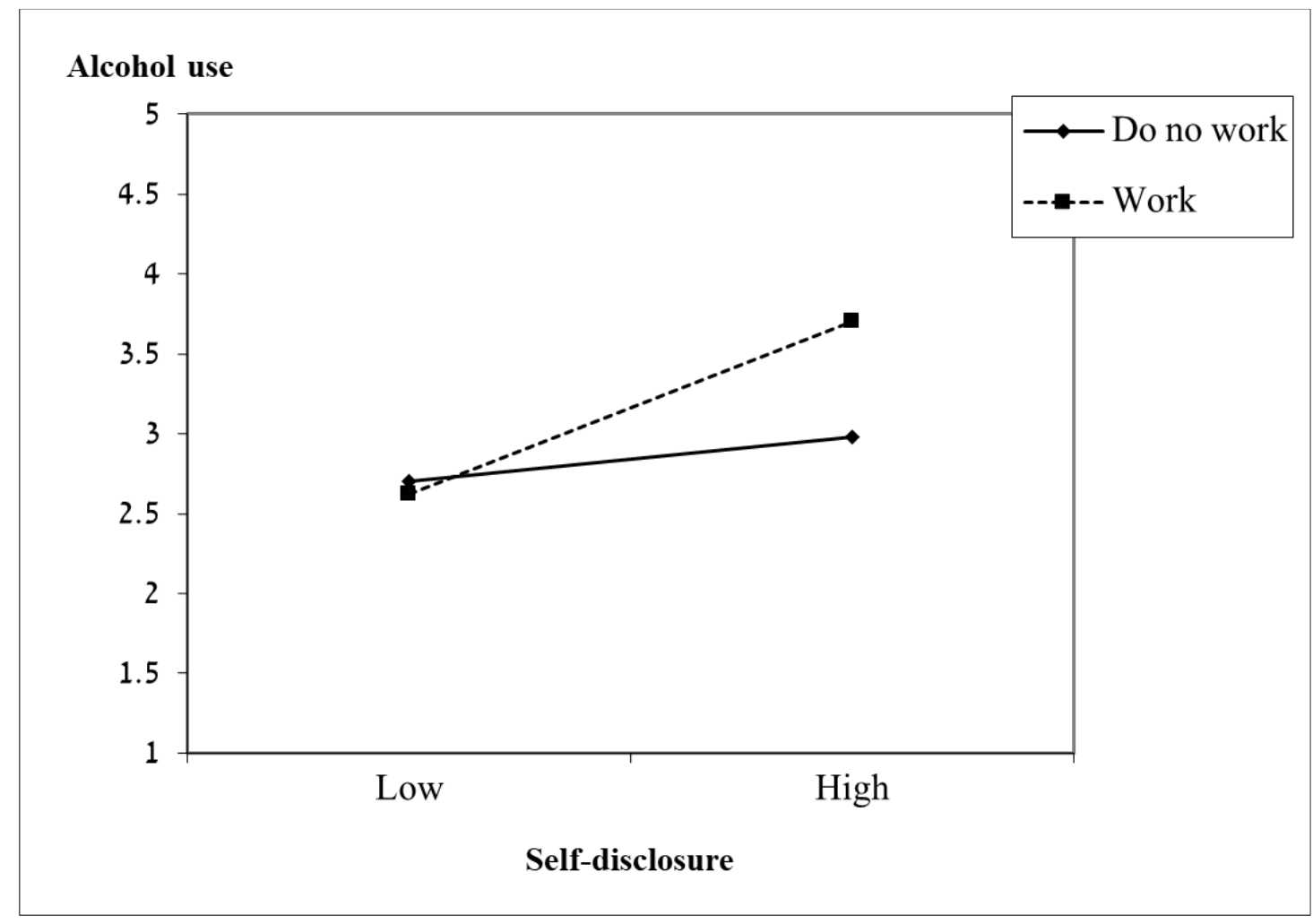

As seen in Figure 3, a significant positive correlation between self-disclosure to friends and drinking was found only among working adolescents $(\beta=-.39, p<.001)$, while among participants who did not work no significant correlation was found $(\beta=-.08, p<.05)$. Thus, among working adolescents, greater disclosure was related to heavier drinking.

\section{Discussion}

The literature differentiates between alcohol consumption among adolescents at risk and normative adolescents. In line with this, the present study was designed to examine the variables (risk factors and resistance factors) that contribute to understanding drinking among adolescents in both groups, using variables identified with the Youth Resiliency model.

The current findings are mostly consistent with international surveys that identified four resilience factors that are strong and consistent, and whose absence in adolescents predicts their disposition toward risk behaviors, including drinking: (1) the presence of a significant adult in the adolescent's life, (2) a daily positive experience in school, (3) a feeling of self-worth, and (4) a feeling of social connectedness. These four factors, which generate wellbeing, are the main foundation for adolescents' mental resilience and for the mental and social stability they need to function (Harel-Fish 2014).

The findings revealed that adolescents at risk drink more than normative adolescents enrolled in high school, a finding that could be explained by differences in environment and level of family support (Etzion 2010). Studies have shown that relationships between parents and their at-risk 
adolescent children are more negative and alienated than between normative adolescents and their parents, and is characterized by low cohesion, inconsistency, lack of openness, poor communication, and high levels of conflict (Etzion 2010; Kaduri 2005). For these adolescents, rejection, hostile behavior, and parental criticism combine with lack of boundaries and too much unsupervised autonomy, all of which generate a need to engage in risk behaviors such as drinking as a way to gain parental attention or as a call for help (Cleveland, Gibbons, Gerrard, Pomery \& Brody 2005).

As stated, our main aim in this study was to examine the degree to which we can explain adolescents' drinking, and whether this explanation is different for normative adolescents and for their at-risk counterparts. While there are similarities between the two groups regarding the contribution of the variables to explain drinking, the fact remains that adolescents at risk consume more alcohol than normative adolescents. These findings are supported by the Youth Resiliency model, according to which the presence or absence of four main factors - significant adult, positive experience in school, a sense of self-worth, and a sense of healthy social connectedness - can serve either as resilience factors or risk factors for the mental wellbeing of children and adolescents. Enhancing these factors in the child or adolescent's life could promote their mental and social wellbeing, which could directly reduce their risk behavior (HarelFish 2014). The difference could possibly be explained by the lower coping resources that adolescents at risk have, stemming from their different background environments.

Four personal characteristics - gender, age, religiosity, and work - explained drinking in both groups. Religiosity contributed more than the other variables, so that a higher level of religiosity was correlated to less drinking in both groups. In addition, in the normative group, drinking among religious adolescents was related to their age and the family's socioeconomic status. As for the age $\times$ religiosity interaction, the negative correlation between religiosity and drinking was found only among older normative adolescents, not among the younger ones. The findings here apply to a Jewish population in Israel, and can be generalized that religiosity mitigates drinking, an effect due to the social support and feeling of belonging that the religious community gives its members, the positive role models who represent positive norms, and the values and beliefs it inculcates (Wray-Lake, Maggs, Johnson, Bachman, O'Malley \& Schulenberg 2012). Many Jewish rituals involve drinking wine, and it is possible that viewing wine in this context help mitigate alcohol consumption among adolescents, as they are permitted - even required to drink - under supervised and specific conditions (Michalak, Trocki \& Bond, 2007). Furthermore, religious educational institutions imbue norms and values that moderate drinking, which nonreligious institutions do not (Wallace, Yamaguchi, Bachman, O'Malley, Schulenberg \& Johnson 2007). It is possible that religiosity affects only normative older adolescents as at that stage their religious perceptions have ripened, and they are more influenced by their peers than they were in early adolescence.

As mentioned, a contribution was also found in a significant interaction between socioeconomic status and religiosity. It was found that level of religiosity is important only among normative adolescents of good socioeconomic status - the more religious they are, the less they drink. This finding may indicate that for adolescents who grow up in low socioeconomic conditions, religiosity does not mitigate drinking, and they are drawn to alcohol as an escape. In addition, families of low socioeconomic status may have less control and a lower ability to supervise their children due to longer work hours. Thus, the effect of peers - especially marginal ones - is stronger, which may lead to frequent overdrinking with friends (Adler \& Wanzer 2005; Etzion 2010). This is consistent with findings that adolescents who live in poverty are more likely to use drugs and alcohol and exhibit violent behavior (Etzion 2010; Horowitz \& Brosh 2011). 
Age and work were also found to contribute to explaining drinking; in both groups, older adolescents who worked drank more. This is consistent with previous studies that indicated that the rate of drinking among adolescents increases with age (Harel-Fish et al. 2014; Tessler 2015). A possible explanation could be that such drinking is part of one's identity-forming process, where adolescents use the peer group as a place to test boundaries, compare themselves to others, and engage in self-examination (Michael \& Ben-Zur 2007). The older the adolescents, the more they are affected by their peer group, and this includes impact on their risk behaviors. The level of conformity increases with age, as does the time adolescents spend with their peers away from their watchful parents, a situation that offers more opportunities for negative experimentation, including experimenting with drinking.

Regarding the work variable, previous studies (Dagan 2016; Staff et al. 2010) also revealed a positive correlation between the number of hours at work and adolescent drinking, without establishing a causal connection.

Gender also contributed to the variance. In both groups, boys drank more than girls, possibly because boys are more affected by the peer group than are girls, especially as related to risk behaviors (Etzion 2010; Michael \& Ben-Zur 2007). Furthermore, boy's judgement is more warped than girls' and these warps give boys a sense of invincibility and immortality (Alberts et al. 2007). Furthermore, in accordance with the Social Construct theory, society and culture affect the formation of gender roles. As overdrinking is an expression of masculine behavior, both men and women fall into obeying these stereotypes (Dagan 2016).

Another prominent contributor to alcohol consumption was an avoidant style, which contributed only among normative adolescents - the higher the avoidance measures, the less the adolescent drank. These finding indicate that the avoidant factor alone explains adolescents' alcohol use, while the anxious one does not affect it. It is possible that lonely adolescents, who lack meaningful social ties, drink less because they perceive drinking as a social need, or because drinking involves peer pressure (Horowitz \& Brosh 2011; Patrick et al. 2012).

Conversely, among adolescents at risk, avoidance did not contribute to explaining the variance of drinking, perhaps because in this group alcohol is a norm that is not related to their social situation. While normative adolescents drink out of a need to belong to their peer group, adolescents at risk may have other reasons, such as mental distress and socioeconomic situation. Indeed, Horowitz and Brosh (2011) found that normative adolescents were more likely to cite social pressure as a reason for drinking, whereas their at-risk counterparts cited escape and seeking pleasant feelings.

Despite findings in the literature that anxious attachment is positively correlated to drinking (Kassel et al. 2006; Molnar et al. 2010), this was not found in the present study. The literature states that individuals with an avoidant style are more concerned than those with other styles about the being appreciated and approved of by others. Consequently, they view drinking as a way to be part of society and avoid rejection, as well as a thrill meant to reinforce positive emotional responses and stifle negative ones (Molnar et al. 2010).

Another variable that contributed to explaining the variance of drinking in the two groups was disclosure to parents, friends, and teachers. The more adolescents - in both groups - disclosed themselves to parents and teachers the less they drank, and the more they disclosed themselves to friends, the more they drank. The Youth Resiliency model (2014) could explain this finding, as could studies that showed that a supportive family with an atmosphere of solidarity, and with a good relationship with parents who both support their children and set boundaries for them, are protective factors that decrease the chance of risk behaviors (Cleveland et al. 2005; Kahan-Strawczynsky, Levi \& Constantinov 2010). 
At the same time, as part of the separation-individuation process, the peer group assumes a major spot in adolescents' lives, and is a source of social support, but also a possible source of temptation and risk. "Entry requirements" into the peer group may call for taking risks and seeking thrills to achieve self-identity in the groups or improve their social standing within it (Jessor et al. 2006; Tessler 2015). As drinking is perceived as a social act (Horowitz \& Brosh 2011; Patrick et al. 2012), most adolescents who experiment with drinking do so for fun and as a pastime, not as an expression of a mental or social problem. This can explain the contribution of self-disclosure to friends to drinking, even among normative adolescents (Horowitz \& Brosh 2011).

Social atmosphere and social pressure are also causes of adolescent drinking. Adolescents at risk, more than their normative counterparts, live in an alcohol-consuming environment. Therefore, they may be more tempted to drink to become part of the group, or because of peer pressure. Alcohol is perceived as prevalent and legitimate among all adolescents, a notion that could draw normative adolescents to consume it in social settings. This is consistent with the theory of Reasoned Action, according to which people's attitudes toward a given behavior (e.g, drinking) are a result of their beliefs and the beliefs of those in their social environment regarding the consequences of this behavior (Fishbein \& Azen 1975). The present study reveals a similarity between both groups regarding the contribution of self-disclosure to parents and friends and alcohol consumption. However, we may assume that its effect will differ, with binge drinking being more prevalent and dangerous among the at-risk group than among the normative one.

It is noteworthy that in the normative group, self-disclosure to friends contributed to explain variance only among adolescents who did not work, not among those who do not work, a finding that was manifested in the significant contribution of the interaction work $\times$ self-disclosure to friends. The interaction reveals that a significant positive correlation between self-disclosure to friends and drinking was found only among participants who worked in addition to going to school or being in a CYC setting. A possible explanation is that these adolescents are better off financially and they can drink more when they are in a social setting that encourages drinking. Another possible explanation is that they have a more developed social circle than their counterparts who do not work, leading them to drink with friends as an expression of social norms.

At the same time, the findings in the present study show a negative correlation between selfdisclosure to parents and drinking in both groups. It is possible that adolescents at risk who disclose themselves to their parents have less conflicts with them, and therefore drink less. This is consistent with previous studies that indicated that adolescents at risk who have a more conflictual relationship with their parents tend to attach themselves to marginal groups to compensate for the defective family system, and such attachment could lead to risk behaviors (Etzion 2010). It is also possible that among adolescents at risk, a high level of parental supervision is a major defense against drinking (Dever et al. 2012). In fact, increased parental supervision may lessen the negative effect of alcohol-consuming friends on the adolescent (Borsari, Murphy \& Barnett 2007), so that despite the conflictual relations in families of adolescents at risk, high parental supervision greatly mitigates drinking.

We may assume that parental support is related to the frequency of alcohol consumption in both groups. Parents who are both significant and available give their child a sense of comfort, leading to the child's willingness to share thoughts and feelings, and avoid risk behaviors.

As mentioned, the self-disclosure to teachers variable also contributed to explain the variance in alcohol consumption in both groups, with higher self-disclosure related to lower consumption. The support of teachers and other adults in school is an important factor in the integration of 
adolescents at risk in school, and in preventing of their dropping out. As adolescents at risk usually receive less social support than their normative peers, this support is of greater importance for them than for normative adolescents (Harel-Fish et al. 2014; Kurt \& Ergene 2017; Lopez et al. 2002).

Interestingly, in this study, no correlation was found in either group between self-esteem and drinking, a departure from the Youth Resiliency model and from previous studies that showed a negative correlation between these two variables (DeHart et al. 2009; Korn \& Maggs 2004). Another variable - self-image - which is correlated to self-esteem, can be called in to explain this finding. It seems that the value of the self-esteem of those engaging in overdrinking can be perceived as higher than that of a person who does no drink; therefore, overdrinking can be a result of the adolescent's desire to be like a typical drinker who he or she values more than they value themselves (Markus \& Nurius 1986). Consequently, adolescents with low self-esteem could participate in drinking. This explanation can be supported by a longitudinal study conducted in Finland, in which no correlation was found between self-esteem and overdrinking (Poilolainen, Tuulio-Henrikson, Aalro-Setala, Marttunen \& Lonnqvist 2001).

\section{Conclusion}

It is important to understand drinking among all adolescents, and most specifically among those at risk, a population where overdrinking is highly prevalent. The present study examined personal characteristics and personality variables according to the Youth Resiliency model, aiming to expand our knowledge of adolescent drinking and map out the predictive risk and resilience factors, as does the model.

As the variables contributing to drinking were similar in the two groups, the Youth Resilience model can be used for both to explain alcohol consumption. Most prominent among the contributing variables were personal characteristics (gender, age, religiosity, and work), avoidance, and self-disclosure to friends, parents and teachers.

Among the personal characteristics, religiosity contributed more than the other variables, and was a protective factor against drinking in both groups. However, while religiosity was a protective factor for all adolescents at risk, it acted as such in the normative group only among the older adolescents and those who are working and earning. It seems that religiosity mitigates drinking for two main reasons. First, the religious community offers its members social support and sense of belonging, and second, it has a solid set of values and norms for educating the younger generation, including clearly defined appropriate and inappropriate behaviors. Another finding was that being male, being an older adolescent, and working are risk factors for drinking.

Among the personality variables examined, self-disclosure to parents and friends was found to be a major contributor to drinking. However, the effect is dichotomous - disclosure to friends is a risk factor, while disclosure to parents is protective. We may then assume that an experience of social connectedness and support does not always act as a resilient factor, as per the Youth Resilience model, but could - under certain condition - be a risk factor. Thus, self-disclosure strongly influences adolescents' drinking, and the findings point to the importance of parental supervision and parent-child communication as a defense against all risk behaviors, including alcohol consumption. Furthermore, it seems that most adolescents view drinking as a social act, so that they may turn to drinking as part of their need to belong to their peer group, or because they feel social pressure to drink. In addition, relationships with friends who are involved in risk behaviors increase the chances for adolescents' involvement in these behaviors and are predictors of risk behaviors. In other words, willingness to disclose themselves to peers 
increases adolescents' risk of drinking, as they then spend time with friends who are in a situation similar to theirs.

An avoidant attachment style was another personality predictor of drinking revealed in this study, and it contributed only among normative adolescents, strengthening the argument that in the normative group drinking begins as a social act. Therefore, those with a strong avoidance measures avoid meaningful interpersonal relationships, drink less, and are thus at lower risk to overdrink.

\subsection{Research limitations and suggestions for future studies}

The present study revealed a similarity between the contribution of personal characteristics and personality characteristics to explain variance in the degree of drinking among at-risk adolescents and their normative counterparts. Recommendations for future research would be for studies that examine the contribution of cognitive characteristics, such as level of selfefficacy, values, parents' attitudes, friends' attitudes, and the adolescents' attitudes toward psychoactive substances. All these measures, found to be involved in drinking, could act as distinguishing predictors between these two groups.

One of the factors that contributed to explaining the variance in drinking in the two groups was the nature of the relationship between adolescents and their parents and peers, as measured by self-disclosure and attachment. However, as the literature identifies different mechanisms used by parents and peers, which affect drinking, future studies should closely examine which mechanisms are involve with drinking among normative adolescents and among at-risk adolescents.

Future studies should also examine the correlations between drinking and other risk behaviors, among them drug abuse, sexual behavior, reckless driving, and violence. Identifying such correlations could help health and therapeutic authorities construct a comprehensive prevention program to deal with risk behaviors. In addition, because adolescents in both groups have clearly distinct school experiences and emotions, future studies should examine the relationship between these experiences and emotions and alcohol consumption in both groups.

On a practical level, the fact that the same factors explain variance in drinking among the two groups, enables those dealing with adolescent drinking to adopt similar interventions for normative and at-risk adolescents. One recommendation is to focus on interventions for older adolescent boys who are not religious and of a low socioeconomic status, as they are at higher risk of drinking. The finding that self-disclosure to parents protects from alcohol consumption, it is important to work with parents toward increasing their involvement in their adolescent children's lives, emphasizing an open relationship, one of warmth, love, concern, and care alongside supervision.

\section{References}

Adam, B, Butler, AB, Dodge, KD, \& Faurote, EJ 2010, College student employment and drinking: A daily study of work stressors, alcohol expectancies, and alcohol consumption. Journal of Occupational Health Psychology, Vol.15, no. 3, pp. 291-303. https://doi.org/10.1037/a0019822

Adler, H \& Wazner, Y 2005, 'A discussion of the situation of young people', in G Rahav, Y Wazner \& M Wander-Schwartz (eds.), Youth in Israel 2004, The Bob Shappel School of Social work, Interdisciplinary Center for the Study of Policy and Care for Children and Youth, Tel Aviv University, Tel Aviv, pp.11-21 (Hebrew). 
Alberts, A, Elkind, D \& Ginsberg, S 2007, 'The personal fable and risk-taking in early adolescence', Journal of Youth and Adolescence, vol 36, no. 1, pp. 71-76. ISSN 1573-6601. https://doi.org/10.1007/s10964-006-9144-4

Apter, A, Horesh, N, Gothelf, D, Graffi, H \& Lepkifker, E 2001, 'Relationship between self-disclosure and serious suicidal behavior', Comprehensive Psychiatry, vol. 42, pp. 70-75. https://doi.org/10.1053/comp.2001.19748

Bachman, JG, Staff, J, O'Malley, PM, et al. 2011, 'Twelfth-grade student work intensity linked to later educational attainment and substance use: New longitudinal evidence', Developmental Psychology, vol. 47, no. 2, pp. 344-363. https://doi.org/10.1037/a0021027

Backer-Fulghum, LM, Patock-Peckham, JA, King, KM, Roufa, L \& Hagen, L 2011, 'The stressresponse dampening hypothesis: How self-esteem and stress act as mechanisms between negative parental bonds and alcohol-related problems in emerging adulthood', Addictive Behaviors, vol. 37, pp. 477-484. https://doi.org/10.1016/j.addbeh.2011.12.012

Borsari, B, Murphy, JG \& Barnett, NP 2007, 'Predictors of alcohol use during the first year of college: Implications for prevention', Addictive Behaviors, vol. 32, pp. 2062-2086. https://doi.org/10.1016/j.addbeh.2007.01.017

Botvin G \& Griffin, K 2007, 'School-based programmes to prevent alcohol, tobacco and other drug use', International Review of Psychiatry, vol. 19, pp. 607-615. https://doi.org/10.1080/09540260701797753

Bowlby, J 1969, Attachment and loss: Attachment Separation, Basic Books, New York.

Brennan, KA, Clark, CL \& Shaver, PR, 1998, 'Self-report measurement of adult attachment', in JA Simpson \& WS Rholes (eds.), Attachment theory and close relationship, Guilford Press, New York, pp. 46-76.

Brennan, KA, Shaver, PR \& Tobey, AE 1991, 'Attachment styles, gender, and parental problem drinking', Journal of Social and Personal Relationships vol. 8, pp. 451-466. https://doi.org/10.1177/026540759184001

Bryant, AL, Schulenberg, JE, O'Malley, PM, et al. 2003, 'How academic achievement, attitudes, and behaviors relate to the course of substance use during adolescence: A 6-year, multiwave national longitudinal study', Journal of Research on Adolescence, vol. 13, no. 3, pp. 361-397. https://doi.org/10.1111/1532-7795.1303005

Buhrmester, D \& Prager, K 1995, 'Patterns and functions of self-disclosure during childhood and adolescence', in KJ Rotenberg (ed.), Disclosure processes in children and adolescents, Cambridge University Press, p. 10. https://doi.org/10.1017/CBO9780511527746.002

Cleveland, MJ, Gibbons, FX, Gerrard, M, Pomery, EA \& Brody, GH 2005, 'The impact of parenting on risk cognitions and risk behavior: A study of mediation in a panel of African American adolescents', Child Development, vol. 76, pp. 900-916. https://doi.org/10.1111/j.1467-8624.2005.00885.x

Dagan, A 2016, 'Usage patterns and alcohol consumption among female students', MA thesis, Ben-Gurion University of the Negev, Beer-Sheba (Hebrew).

DeHart, T, Tennen, H, Armeli, S, Todd, M \& Mohr, C 2009, 'A diary study of implicit self-esteem, interpersonal interactions, and alcohol consumption in college students', Journal of Experimental Social Psychology, vol. 45, pp. 720-730. https://doi.org/10.1016/j.jesp.2009.04.001

Dever, BV, Schulenberg, JE, Dworkin, JB, et al. 2012, Predicting risk-taking with and without substance use: The effects of parental monitoring, school bonding, and sports participation. Prevention Science, vol. 13, no. 6, pp. 605-615. https://doi.org/10.1007/s11121-012-0288-z

Etzion, D 2010, 'Typology of at-risk adolescents in Israel', PhD thesis, Bar-Ilan University, Israel (Hebrew).

Fishbein, M \& Azen, I 1975, Belief, attitude, intention and behavior: An introduction to theory and research, Addison-Wesley, Reading, MA.

Gençtanırım, D \& Ergene, T 2014, 'Prediction of risk behaviours among Turkish adolescents', International Journal of Social Science, vol. 25, no. 1, 125-138.

Grabill, CM \& Kerns, KA 2000, 'Attachment style and intimacy in friendship', Personal Relationships, vol. 7, no. 4, pp. 363-378. https://doi.org/10.1111/j.1475-6811.2000.tb00022.x 
Grupper, E \& Romi, S (eds.). 2015, Children and adolescents at risk in Israel: Vol. 2: The voice of young people and issues faced by child and youth care workers, MOFET, Tel Aviv (Hebrew). Hodge, DR, Marsiglia, FF, \& Nieri, T 2011, Religion and substance use among youth of Mexican Heritage: A social capital perspective, Social Work Research, vol. 35, no.3, pp. 137-146. https://doi.org/10.1093/swr/35.3.137

Kurt, DG \& Ergene, T 2017, 'Adolescent risk-taking and the five-factor model of personality', Education and Science, vol. 42, no. 189, pp.137-152.

Harel-Fish, Y 2014, 'Youth resiliency: Integrating a useful strategy for the prevention of risk behaviors and the enhancement of the wellbeing of children and adolescents', in R Zimmer \& H BoneyNoah (eds.), Preventing use of drugs and alcohol, Bialik Institute, Jerusalem, pp. 67-83 (Hebrew).

Harel-Fish, Y, Steinmetz, S, Lubel, S \& Tessler, R 2014, Youth in Israel: Usage patterns and attitudes toward addictive substances. Summary of 2014 national study. Bar-Ilan University, Israel (Hebrew).

Horowitz, T \& Brosh, T 2011, Alcohol use among adolescent immigrants from the CIS. Israel AntiDrug Authority, Jerusalem (Hebrew).

Jessor, R, Costa, FM, Krueger, PM \& Turbin, MS 2006, 'A developmental study of heavy episodic drinking among college students: The role of psychosocial and behavioral protective and risk factors', Journal of Studies on Alcohol, vol. 67, pp. 86-94. https://doi.org/10.15288/jsa.2006.67.86

Kaduri, T 2005, 'Testing the validity of a self-report questionnaire for attachment styles of adolescents at risk: The relationship between these patterns, interpersonal narratives, and adjustment', MA thesis, Bar-Ilan University, Israel (Hebrew).

Kahan-Strawczynsky, P, Levi, D \& Constantinov, Z 2010, Adolescent immigrants in Israel: An updated portrait. Myers-Joint-Brookdale, Jerusalem (Hebrew).

Kaim, Z \& Romi, S 2016. 'Help seeking according to the components of the "Threat to Self-esteem" model: A comparison between at-risk and normative adolescents', Megamot (Trends), vol. 51, no. 1, pp. 185-212 (Hebrew).

Kaim, Z \& Romi, S 2015, 'The youth care worker as a resource for adolescents at a risk seeking help', Children and Youth Services Review, vol. 53, pp. 17-23. https://doi.org/10.1016/j.childyouth.2015.03.002

Kassel, JD, Wardle, M \& Roberts, JE 2006, 'Adult attachment security and college substance use', Addictive Behaviors, vol. 32, no. 6, pp. 1164-1176. https://doi.org/10.1016/j.addbeh.2006.08.005

Kipnis, A 2014, 'Overdrinking among young adults (18-35) in Israel: Implementation of the Planned Behavior theory and the role of self-esteem', MA thesis, University of Haifa (Hebrew).

Korn, ME \& Maggs, JL 2004, 'Why drink less? Diffidence, self-presentation styles, and alcohol use among university students', Journal of Youth and Adolescence, vol. 33, pp. 201-211. https://doi.org/10.1023/B:JOYO.0000025319.57979.13

Lepple, K 2006, College binge drinking: deviant versus mainstream behavior. American Journal of Drug and Alcohol Abuse, vol. 32, no. 4, pp. 519-25. https://doi.org/10.1080/10623320600919144

Markus, H \& Nurius, P 1986, Possible selves. American Psychologist, vol. 41, pp. 954-969. https://doi.org/10.1037/0003-066X.41.9.954

Merline, A, Jager, J \& Schulenberg, JE 2008, 'Adolescent risk factors for adult alcohol use and abuse: Stability and change of predictive value across early and middle adulthood', Addiction, vol. 103, pp. 84-99. https://doi.org/10.1111/j.1360-0443.2008.02178.x

Michael, K \& Ben-Zur, H 2007, Risk-taking among adolescents: Associations with social and affective factors. Journal of Adolescence, vol. 30, pp. 17-31. https://doi.org/10.1016/j.adolescence.2005.03.009

Michalak, L, Trocki, K, \& Bond, J 2007, Religion and alcohol in the U.S. National Alcohol Survey: How important is religion for abstention and drinking?. Drug and Alcohol Dependence, vol. 87, no. 4, pp. 268-280. https://doi.org/10.1016/j.drugalcdep.2006.07.013

Molnar, DS, Sadava, SW, DeCourville, NH \& Perrier, CPK 2010, 'Attachment, motivations, and alcohol: Testing a dual-path model of high-risk drinking and adverse consequences in transitional clinical and student samples', Canadian Journal of Behavioural Science, vol. 42, pp. 1-13. https://doi.org/10.1037/a0016759 
Nakimuli-Mpungu, E \& Munyaneza, G 2011, 'Depression, alcohol abuse, and disclosure of HIV serostatus among rural HIV-positive individuals in western Uganda', Neurobehavioral HIV Medicine, vol. 3, pp. 19-25. https://doi.org/10.2147/NBHIV.S13277

National Health Service (NHS) 2012, Statistics on alcohol, England 2012. Retrieved from https://catalogue.ic.nhs.uk/publications/ publichealth/ alcohol/alco-eng-2012/alco-eng-2012-rep.pdf

Neumann, CA, Leffingwell, TR, Wagner, EF, Mignogna, J \& Mignogna, M 2009, 'Self-esteem and gender influence the response to risk information among alcohol using college students', Journal of Substance Use, vol. 14, pp. 353-363. https://doi.org/10.3109/14659890802654540

Parker, JS \& Benson, MJ 2004, 'Parent-adolescent relations and adolescent functioning: Selfesteem, substance abuse, and delinquency', Adolescence, vol. 39, no. 155, pp. 519-530.

Patrick, ME \& Schulenberg, JE 2014, 'Prevalence and predictors of adolescent alcohol use and binge drinking in the United States', Alcohol Research, vol. 35, no. 2, pp. 193-200.

Patrick, ME, Schulenberg, JE, Maggs, JL \& Maslowsky, J 2012. 'Substance use and peers during adolescence and the transition to adulthood: Selection, socialization, and development', in K Sher (ed.), Handbook of substance use disorders, Oxford University Press, New York.

Pearlin, LI \& Schooler, C 1978, 'The structure of coping', Journal of Health and Social Behavior, vol. 24, pp. 2-15. https://doi.org/10.2307/2136319

Piko BF, Kovacs E, Kriston, P \& Fitzpatrick KM 2012, "To believe or Not to believe?" Religiosity, spirituality and alcohol use among Hungarian adolescents', Journal of Studies on Alcohol and Drugs, vol. 73, no. 4, pp. 666-674. https://doi.org/10.15288/jsad.2012.73.666

Poikolainen, K, Tullio-Henriksson, A, Aalto-Setala, T, Marttunen, M \& Lonnqvist, J 2001, 'Predictors of alcohol intake and heavy drinking in early adulthood: A 5-year follow-up of 15-19-year-old Finnish adolescents', Alcohol and Alcoholism, vol. 36, no. 1, pp. 85-88. https://doi.org/10.1093/alcalc/36.1.85

Rosenberg, M 1965, Society and the adolescent self-image. Princeton University Press, Princeton, NJ. https://doi.org/10.1515/9781400876136

Shulman, SH, Laursen, B, Kalman, Z, Karpovsky, S 1997, 'Adolescent intimacy revisited', Journal of Youth and Adolescence, vol. 26, no. 5, pp. 597-617. https://doi.org/10.1023/A:1024586006966

Staff, J, Schulenberg, JE, Maslowsky, J, et al. 2010, 'Substance use changes and social role transitions: Proximal developmental effects on ongoing trajectories from late adolescence through early adulthood', Development and Psychopathology, vol. 22, no. 44, pp. 917-932. https://doi.org/10.1017/S0954579410000544

Tessler, R 2015, 'Health-enhancement policy at the school level, and student-level factors that predict patterns of health risk-behaviors and a subjective sense of wellbeing among adolescents: A multilevel analysis', PhD thesis, Haifa University, Israel (Hebrew).

Van der Vorst, H\& Engels, R 2006, 'Parental attachment, parental control, and early development of alcohol use: A longitudinal study', Psychology of Addictive Behaviors, vol. 20, pp. 107-116. https://doi.org/10.1037/0893-164X.20.2.107

Vogel, DL \& Wei, M 2005, 'Adult attachment and help-seeking intent: The mediating roles of perceived social support and psychological distress', Journal of Counseling Psychology, vol. 52, no. 3, pp. 347-357. https://doi.org/10.1037/0022-0167.52.3.347

Wallace, JM, Jr, Yamaguchi, R, Bachman, JG, O'Malley, PM, Schulenberg, JE \& Johnston, LD 2007, 'Religiosity and adolescent substance use: The role of individual and contextual influences', Social Problems, vol. 54, no. 2, pp. 308-327. https://doi.org/10.1525/sp.2007.54.2.308

Werch, CE, Carlson, JM, Owen, DM, DiClemente, CC \& Carbonari, JP 2001, 'Evaluation of a brief alcohol prevention program for urban school youth', American Journal of Health Behavior, vol. 24, pp. 120-131. https://doi.org/10.5993/AJHB.24.2.5

White, HR, Johnson, V \& Buyske, S 2000, 'Parental modeling and parenting behavior effects on offspring alcohol and cigarette use: A growth curve analysis', Journal of Substance Abuse, vol. 12, no. 3, pp. 287-310. https://doi.org/10.1016/S0899-3289(00)00056-0

Wray-Lake, L, Maggs, JL, Johnston, LD, Bachman, JG, O'Malley, PM \& Schulenberg, JE 2012, 'Associations between community attachments and adolescent substance use in nationally representative samples', Journal of Adolescent Health, vol. 51, no. 4, pp. 325-331. https://doi.org/10.1016/j.jadohealth.2011.12.030 
Zeigler-Hill, V 2011, 'The connections between self-esteem and psychopathology', Journal of Contemporary Psychotherapy, vol. 41, pp. 157-164. doi:10.1007/s10879-010-9167-8 